\title{
Em nome dos cuidados, da proteção e da educação: infância, corpo, gênero e sexualidade como discursos entre professoras da Educação Infantil
}

Resumo: Este artigo tem como objetivo compreender os discursos de professoras, de uma instituição de Educação Infantil da rede pública, sobre o corpo da criança, nos modos como estes se entrelaçam com as práticas de educar, cuidar, proteger e como são atravessados por perspectivas de gênero e sexualidade. Como referenciais teóricos, destacam-se os estudos da infância, bem como as análises de Michel Foucault, David Le Breton, Donna Haraway e Judith Butler, que, resguardadas as suas diversidades teóricas, permitem compreender corpo, gênero e sexualidade numa dimensão discursiva. Os discursos das professoras remetem a práticas de cuidar, educar e relações de gênero vividas no cotidiano da instituição, que trazem à tona questões sobre o corpo da criança, em suas mais intensas alteridades em relação ao corpo adulto, civilizado e disciplinado.

Palavras-chave: Infância. Corpo. Gênero. Educação Infantil.

\section{In the name of care, protection and education: childhood, body, gender and sexuality as discourses among preschool teachers}

\begin{abstract}
This article aims to comprehend the discourses, shared with preschool teachers, of an Early Childhood Education public institution, about childhood body, focusing on the ways these are interconnected with practices of education, care, protection and how they are crossed by gender and sexuality perspectives. As theoretical references, we highlight the childhood studies, as well as Michel Foucault, David Le Breton, Donna Haraway and Judith Butler analysis, which, despite of their theoretical diversities, permit to comprehend body, gender and sexuality in a discursive dimension. Teachers's discourses refer to practices of care, education and gender relations experienced in everyday life of this institution, which bring up questions on child's body, in its more intensive alterity in relation to adult, civilized and disciplined body.
\end{abstract}

Keywords: Childhood. Body. Gender. Early Childhood Education.

\footnotetext{
1 Doutora em Psicologia (Psicologia Clínica) pela Pontifícia Universidade Católica do Rio de Janeiro. Professora Associada do Programa de Pós-graduação em Educação e do Curso de Psicologia da Universidade Federal de Mato Grosso, Campus de Rondonópolis. E-mail: ramidan@terra.com.br

2 Graduanda em Psicologia pela Universidade Federal de Mato Grosso - Campus Universitário de Rondonópolis. E-mail: paula.fernanda_@hotmail.com
} 


\section{De onde partem nossas questões}

inocência consagra-se como um atributo fundante da infância no mesmo instante em que a
família nuclear e a escola se constituem como instituições que passam a produzir e gerir um
conjunto de discursos e práticas indispensáveis para os processos de subjetivação das crianças, em suas relações com os adultos, no capitalismo moderno ocidental, a partir do século XVII. A partir dessa nova ordem social e econômica, a ideia de inocência acopla-se, de tal maneira, ao conceito de infância, a ponto de essa imbricação se tornar algo incontestável. A inocência, portanto, assume o caráter de "natureza infantil".

O binômio criança- inocência institui-se, assim, como um dos pilares de sustentação da ontologia da infância produzida, sobretudo, pelo pensamento moderno ocidental. Neste artigo, um dos eixos de problematização que adotamos é a indagação dos discursos que consolidam esse binômio ao assumirmos o gênero e a sexualidade como vieses de interrogação. Neste sentido, as questões que aqui levantamos partem de uma compreensão dos discursos, compartilhados entre professoras de Educação Infantil, sobre o corpo da criança, com foco nos modos como estes se entrelaçam com as práticas de educar, cuidar, proteger e como são atravessados por perspectivas de gênero e sexualidade.

A pesquisa ${ }^{3}$, de onde partem estas reflexões, compõe uma das linhas do grupo de pesquisa “Infância, Juventude e Cultura Contemporânea" (GEIJC), pertencente ao Programa de Pós-graduação em Educação (PPGEdu), da Universidade Federal de Mato Grosso (UFMT), do Câmpus de Rondonópolis, Mato Grosso. Seu contexto foi uma instituição de Educação Infantil da rede pública municipal dessa cidade, denominada como Centro Municipal de Ensino Infantil (CMEI), que recebe crianças de 0 a 5 anos, pertencentes à creche e à pré-escola, organizadas em turmas de turnos parcial e integral. Nesse contexto, realizamos uma pesquisa intervenção, em que as relações estabelecidas entre as pessoas participantes e as pesquisadoras suscitam reflexões no contexto da própria investigação. A produção discursiva, que se processa nessas relações, é tida como eixo de análise. Nessa dupla dimensão da pesquisa, tanto as crianças quanto as professoras não são informantes de dados a serem traduzidos pelo texto analítico das pesquisadoras, de modo que a investigação se constitui nas relações construídas entre as pesquisadoras, as crianças, as professoras e as auxiliares da instituição. Além disso, é importante ressaltar

${ }_{3}^{3}$ Participaram como auxiliares da pesquisa as estudantes de graduação em Psicologia (UFMT/Rondonópolis) Elayne Eva Borges Araújo (bolsista de Iniciação Científica), Bruna Padilha Gonçalves (voluntária de Iniciação Científica) e Paula Fernanda Martins Garcia (voluntária de Iniciação Científica). 
que a pesquisa também se constrói a partir das concepções de mundo, experiências, valores e práticas das pessoas envolvidas.

Como recursos metodológicos, destaca-se a observação participante das relações entre as crianças, as professoras e as auxiliares de higienização, em seus mais diversos contextos de convivência, abarcando situações de diálogos entre essas pessoas e as pesquisadoras. Os acontecimentos observados foram registrados em diário de campo.

Participaram da pesquisa de campo crianças, professoras e auxiliares de higienização de quatro turmas, especificamente: trinta e uma crianças na turma de 2 anos de turno integral; vinte e sete crianças na turma de 3 anos de turno integral; vinte e duas crianças na turma de 3 anos de turno parcial; e vinte e uma crianças na turma de 5 anos de turno parcial. Nas turmas de turno integral, participaram as professoras e auxiliares do período matutino. Vale ressaltar que a escolha das turmas se deu em função de dois critérios básicos: as idades das crianças (pequenas - de $2 / 3$ anos - e maiores - de 5 anos) e os turnos (parcial e integral).

Embora tenhamos trabalhado com as crianças no processo de pesquisa, para atender ao escopo deste artigo, dedicamo-nos à análise dos discursos compartilhados pelas professoras da instituição educativa. Desse modo, analisamos, além dos discursos que circularam na instituição durante o desenrolar da pesquisa de campo, aqueles que foram produzidos em uma roda de conversa com o grupo de professoras, realizada na própria instituição, sobre questões que remetem ao corpo da criança e se fazem presentes em suas práticas pedagógicas.

Para dar início à roda de conversa, levamos uma caixa com tiras de papel dobradas, nas quais estava escrita uma palavra chave da pesquisa. Denominamos como palavras chave da pesquisa aquelas elencadas a partir das observações e registros feitos durante a pesquisa de campo na instituição e que mantêm relações diretas com as práticas de cuidado e educação das crianças. Após mostrarmos a caixa e dizermos o que ela continha, solicitamos às professoras que cada uma, por vez, pegasse uma tira de papel dobrada de dentro dela e lesse em voz alta para o grupo a palavra escrita. Como aconteceu apenas uma roda de conversa até o presente momento, não foi possível trabalharmos com todas as palavras chave por nós elencadas, de modo que, nesse primeiro encontro, foram lidas e discutidas pelas professoras as palavras "feminino", "sexualidade", "racismo" e "disciplina". Neste artigo, entretanto, dedicamo-nos a analisar os diálogos suscitados a partir das palavras "feminino" e "sexualidade".

A relevância deste trabalho consiste em trazer para o cenário da educação de crianças pequenas questões que ainda estão sufocadas por entrarem em choque com uma imagem secular da infância, que, mesmo modificada, ainda se mantém em vigor. São questões que trazem à tona o corpo da criança, com suas singularidades, prazeres, demandas, cuidados e suas mais intensas alteridades em relação ao corpo adulto, civilizado, educado e disciplinado. 


\section{Corpos disciplinados, cuidados e protegidos: aqueles que não podem se tocar}

É sabido que a moral sexual, na sociedade ocidental, protagonizou a consolidação do conceito de infância no século XVII, como mostra Ariès (1981). A sexualidade das crianças foi, nesse contexto histórico, o grande divisor de águas entre a infância e a vida adulta. Vigiadas e perseguidas, as experiências sexuais das crianças precisavam ser esquadrinhadas e controladas.

Foucault (2006), também, analisa como a sexualidade, a partir do século XVII, passa a ter visibilidade ao ser perseguida e confiscada. Ela é encerrada dentro de casa, sobretudo no quarto do casal, com a função de reproduzir.

O casal, legítimo e procriador, dita a lei. Impõe-se como modelo, faz reinar a norma, detém a verdade, guarda o direito de falar, reservando-se o princípio do segredo. No espaço social, como no coração de cada moradia, um único lugar de sexualidade reconhecida, mas utilitário e fecundo: o quarto dos pais. Ao que sobra só resta encobrir-se; o decoro das atitudes esconde os corpos, a decência das palavras limpa os discursos. E se o estéril insiste, e se mostra demasiadamente, vira anormal: receberá este status e deverá pagar as sanções. (FOUCAULT, 2006, p. 10, grifo do autor).

Entretanto, para o autor, muito mais importantes do que as práticas de repressão são os discursos de verdade sobre o sexo: o que se fala, como se fala, que instituições falam e sob que pontos de vista. Ao ser colocada como discurso, a sexualidade se consagra como um dispositivo de poder. Essas produções discursivas de verdade carregam uma "vontade de saber", que lhes dão suporte e as instrumentalizam. Nessa linha de pensamento, Foucault (2006) argumenta o quanto é equivocado afirmar que as instituições pedagógicas, no século XVIII, impôs um silêncio rigoroso à sexualidade das crianças e dos adolescentes. Ao contrário, houve uma convergência de discursos sobre esse assunto: pais, médicos, educadores, administradores, todos se ocupam de um mesmo objetivo - falar da sexualidade das crianças, incitaremnas a falar, enredá-las numa teia discursiva, da qual não possam escapar ilesas, sem terem seus corpos e desejos penetrados e formatados por esses dispositivos. Nessa lógica, tudo aquilo que escapa dessa teia, o que se singulariza, não é simplesmente excluído, mas calculistamente especificado e fixado: a sociedade moderna "produz e fixa o despropósito sexual" (FOUCAULT, 2006, p. 55).

O século XVII marca o auge da consagração da inocência infantil na cultura ocidental. A partir desse discurso, as crianças passam a ser concebidas como sujeitos frágeis, incapazes, e subordinados a uma relação de dependência com os adultos que se define pela tutela. $\mathrm{O}$ discurso do binômio infânciainocência produz-se fortemente atrelado a uma moral sexual, também, protagonizada na sociedade moderna ocidental do século XVII, como sinaliza Ariès (1981). Os moralistas se aliaram aos padres, que, instruídos pelos primeiros, passaram a despertar nas crianças um sentimento de culpa. Os tratados de civilidade dessa época são discursos exemplares sobre o corpo: como deve ser, aparecer e apresentar-se. A decência e o decoro nos gestos, nos olhares e nas linguagens ganham notoriedade nos modos como as crianças passam a ser educadas. Muito mais do que se preocupar com o que a criança vive, faz, sente ou pensa, a meta dessa educação era a sua preparação como "homem de bem".

Foucault (2014) afirma que a cultura ocidental foi acometida por um "hiperdesenvolvimento da sexualidade" (p. 57), que remete à constituição de uma ciência sobre a sexualidade, uma scientia sexualis. O 
século XVII, diz ele, institui uma “teologia moral” (p. 59), cuja ambição é dizer a verdade da sexualidade e nunca a intensidade do prazer. Embora o Cristianismo, na sociedade ocidental, tenha dado contribuições efetivas para a produção de técnicas que vão implementar uma moral sexual - haja vista a prática da confissão pastoral -, Foucault (2014), ancorado nos estudos do historiador Paul Veyne, esclarece que a regra da monogamia, a procriação como função exclusiva da sexualidade e a desqualificação do prazer sexual (assumido como um malefício) já se fazem presentes no mundo romano e, portanto, não são discursos e práticas originários do Cristianismo. O que este traz de novidade são as técnicas que funcionam como mecanismos de poder e se articulam para a produção de uma verdade. A grande questão posta pela moral cristã é o exercício da confissão, em que o corpo é exaustivamente examinado como forma de saber as "coisas indecentes" que nele se produzem. Faz-se urgente conhecer a interioridade dos sujeitos. Trata-se de uma técnica de tomada de consciência sobre si mesmo, sobre as vulnerabilidades do corpo, que precisa travar um combate cotidiano às vicissitudes do prazer.

Instaura-se um sistema poder-saber-prazer, argumenta Foucault (2006), no qual a sexualidade das crianças, muito mais do que inimigo a ser combatido, aparece como suporte de práticas de vigilância e fiscalização, que se efetivam mediante a sua incitação. Nessa lógica, a eficácia do poder afirma-se ao passo que o seu alvo se dispersa e se difunde de forma ramificada, configurando, no tecido social, "linhas de penetração infinitas" (FOUCAULT, 2006, p. 50). As sexualidades, portanto, são convocadas a se manifestar das formas mais diversas para que sejam esquadrinhadas e, portanto, passíveis de categorizações, que produzem corpos e sujeitos. Instituições psiquiátricas, escolas e famílias são partícipes ativos desse trabalho classificatório, pois, como analisa Foucault (2006, p. 52), o “exame médico, a investigação psiquiátrica, o relatório pedagógico e os controles familiares funcionam como mecanismos de dupla incitação: prazer e poder.”

No CMEI, a presença de discursos que, ao mesmo tempo, afastam das crianças a sexualidade e a identificam nas experiências que elas compartilham, como forma de vigilância e disciplina, é intensa entre as professoras e as auxiliares, em suas relações com as crianças.

No excerto abaixo, extraído do diário de campo de uma das pesquisadoras, nota-se um episódio em que esses discursos vêm à tona:

Finalmente, ela (a professora da turma de crianças de 5 anos do turno parcial) me contou que tem percebido há algum tempo que os gêmeos da turma costumam se abraçar e beijar e que ela se preocupou muito com isso, levando tal questão para a Direção. Segundo ela, a Diretora disse que não poderia fazer nada, mas que ela deveria avisar a mãe sobre o que estava acontecendo. Antes disso, ela procurou a professora da tarde para ver se isto acontecia também no período vespertino, porém a professora negou. Após alguns dias, ela descobriu por parte das auxiliares do turno da tarde que tal fato ocorria nesse turno também. Diante disso, ela chamou a mãe dos meninos para uma conversa. Para ela, tal situação é extremamente complicada por dois motivos: primeiro, o fato de serem crianças e, depois, por serem dois meninos se beijando. Além disso, ela também percebe que eles têm preferências por brincadeiras de menina, como bonecas e bolsinhas. Sobre a conversa com a mãe, ela contou que esta pediu para que ela mantivesse os dois meninos separados, evitando que a situação voltasse a ocorrer, dizendo que ela não permitirá coisas deste tipo em sua casa.

(Excerto extraído do diário de campo de uma das pesquisadoras) 
A professora demonstrou preocupação não apenas com as crianças, mas também em tratar do fato. No dia em que relatou o acontecido, ela se mostrou muito desconfortável em fazê-lo, além de ter demonstrado certa apreensão algumas semanas depois, retomando o assunto ao dizer que, por dias, refletiu se deveria ou não ter feito esse comentário. Esclareceu, ainda, que para ela tal situação fugia completamente do que concebia como "normal", de modo que se caracterizava como algo que precisava ser combatido. Em nenhum momento, houve qualquer tipo de conversa com as crianças a respeito do acontecido. A prática corrente, tanto da professora quanto das auxiliares, tem sido a separação dos dois meninos das demais crianças e de si próprios. Toda e qualquer aproximação entre os meninos é bruscamente impedida por elas.

A sacralização dos corpos das crianças é visível nos discursos dos adultos e aponta para a importância que assume a proteção dos corpos das crianças sob este viés. O cuidado é redobrado frente à sexualidade, que sinaliza um grande risco à manutenção da inocência desses corpos. A sexualidade é regulada até que seja reduzida ao silêncio, de modo que "o decoro das atitudes esconde os corpos, a decência das palavras limpa os discursos. E se o estéril insiste, e se mostra demasiadamente, vira anormal" (FOUCAULT, 2006, p. 10). No caso dos irmãos gêmeos, separá-los significa conter os seus corpos unidos, ao mesmo tempo em que eles precisam aparecer para que estejam na mira da disciplina que insiste em evitar os seus contatos e reagir contra a possibilidade de manifestação de uma suposta homossexualidade.

Le Breton (2013a), ao tratar do corpo na vida cotidiana das sociedades ocidentais, afirma que o seu apagamento é marca de sociabilidade, posto que seu estatuto ideal é o do silêncio, da discrição e até mesmo do escamoteamento, o que caracteriza o estado de saúde. Esse episódio dos impedimentos da professora em relação aos contatos corporais entre os irmãos gêmeos remete-nos aos ritos de evitamento e de regulação dos contatos requisitados pela simbolização dos usos e das relações com o corpo: não tocar o outro; não se aproximar; não compartilhar familiaridades ou intimidades; não mostrar o corpo nu. Tudo isto se intensifica se este corpo estiver encarnado em uma criança por ser alvo privilegiado de uma construção que, segundo Le Breton (2013b), precisa ser realizada sob medida, tornando-se, assim, um empreendimento que necessita ser muito bem gerido e controlado.

$\mathrm{Na}$ instituição, o controle dos corpos das crianças também é feito por meio do discurso religioso, no qual os símbolos sagrados de Deus e de Jesus são usados pelas professoras e auxiliares como mecanismo disciplinador para os comportamentos que escapam de seus domínios: "Jesus não gosta de menino que teima" e "Vamos obedecer, senão o Papai do Céu chora" são frases muito corriqueiras no cotidiano do CMEI.

Aproveitando o momento da oração para Deus, fora usada a figura de um Deus controlador para explicar para as crianças que a sujeira não pode continuar sendo feita, pois, assim, não estariam agradando a Deus, além de desperdiçarem comida. (Excerto extrá́do do diário de campo de uma das pesquisadoras)

O apelo a Deus funciona como um nítido discurso de controle dos corpos das crianças, que funciona sob a forma de vigilância e punição: o que pode acontecer com uma criança que não agrada 
Deus, quem, supostamente, dela cuida e a protege? Tomando como álibis os discursos de proteção e cuidado, culpa e medo instauram-se, caso a rebeldia aconteça.

Corpos de crianças ambíguos, híbridos e que destoam da norma sexual, instituída como um dos fios condutores do desenvolvimento humano, são alvos de atenção, controle e conserto. O corpo infantil, assumido como a encarnação da "inocência original", consiste na gênese de toda história produzida por uma política reprodutiva (HARAWAY, 2016, p. 89). O direito a esse corpo-origem é confiscado da criança, posto que, em nome dos cuidados e da proteção, seus corpos são sempre nomeados e geridos pelos adultos. São esses discursos e práticas sobre os corpos infantis que sustentarão a normalização dos corpos adultos: “a criança é um artefato biopolítico que garante a normalização do adulto.” (PRECIADO, 2013, p. 98).

No conjunto de discursos da sexopolítica, a infância é enunciada como um dispositivo que fundamenta e naturaliza a demarcação entre normalidade e anormalidade e, nessa delimitação, está a requisição de a experiência infantil corroborar uma identidade de gênero normativa (FERREIRA, 2016).

\section{Discursos e dilemas sobre infância, gênero e sexualidade}

Um ano após a realização da pesquisa de campo na instituição, decidimos fazer uma devolutiva do que observamos e registramos durante esse processo, utilizando um procedimento que não fosse apenas a entrega de um relatório ao grupo de professoras, coordenadora e diretora do CMEI, mas que consistisse na apresentação das questões levantadas no decorrer da pesquisa como forma de suscitar reflexões sobre as concepções e práticas que atravessam o cotidiano do trabalho educativo com as crianças. Nesse sentido, propusemos à equipe do CMEI a realização de uma roda de conversa junto ao grupo de professoras, ainda que este não contemplasse todas as professoras que participaram da pesquisa de campo, pois algumas não estão mais atuando na instituição. Tal proposta foi prontamente acatada.

Utilizando a estratégia das palavras chave, descrita anteriormente, apresentamos a caixa e deixamos as professoras à vontade para que uma delas se prontificasse a retirar a primeira palavra e sobre esta tecer comentários". A primeira palavra chave retirada foi "feminino", que suscitou diversas questões e situações trazidas pelas professoras, que remetem a modos de pensar o gênero na sociedade.

Uma dessas questões é a separação binária entre meninos e meninas, como podemos observar no excerto abaixo:

Professora L: Até a questão do banho. Primeiro se banha só as meninas e depois os meninos. No berçário não, a gente vai banhando eles de acordo com quem vai se sujando, né? Mas não tem essa separação, porque eles são crianças, eles não têm is so, o que para os adultos seria uma malícia, o menino olhar a menina sem roupa. Mas isso é cobrado da gente. Vai chegar um momento em que vai ter que fazer isso, separar. Querendo ou não, você vai ter que acabar separando eles.

\footnotetext{
${ }^{4}$ Para efeitos das análises deste artigo, não abordamos os discursos das professoras sobre as três palavras chave retiradas nessa primeira roda de conversa, posto que nos detemos apenas naquelas que mais suscitaram questões relativas ao escopo deste trabalho.
} 
A distinção binária de gênero assume caráter compulsório no discurso da professora, como se fosse uma tarefa inevitável na educação das crianças. Ainda que o contato e a convivência dos corpos sejam tolerados entre os bebês, na medida em que estes se desenvolvem e passam a integrar a categoria de "crianças", a mistura precisa ser vetada e, se esta persiste, vem a cobrança, que certamente não se restringe à instituição ou à rede de ensino, mas circula e penetra em todas as esferas da vida social e subjetiva.

A ideia de uma identidade coerente, unívoca e estável constitui no telos do desenvolvimento humano conduzido por normas de inteligibilidade produzidas e mantidas socialmente, que incluem a coerência e o alinhamento sexo-gênero-sexualidade (BUTLER, 2016). Institui-se, assim, uma noção de pessoa, cuja existência se sustenta na materialidade dessa inteligibilidade. A identidade ocidental consagrase como um estado de posse, de comando do próprio "eu", que tem a identidade de gênero como um de seus tipos (HARAWAY, 2004). Aqueles/as cujos gêneros rompem a coerência e a linearidade não podem existir, pois, ao escaparem dessa inteligibilidade, borram a imagem de pessoa construída por esses discursos normativos.

A ideia de uma identidade de gênero, marcada pela coerência e unicidade, como destaca Judith Butler (2016), se sustenta no binarismo, que é o alinhamento entre sexo e gênero, definido por sua subordinação ao corpo sexuado pela "natureza". Nessa lógica, a masculinidade corresponde a corpos de meninos e homens, assim como a feminilidade a corpos de meninas e mulheres. Trata-se de uma relação mimética, em que o gênero é requisitado a expressar o corpo sexuado. No entanto, para Butler (2016), assim como gênero, o corpo sexuado é produzido e mantido por discursos que o constituem como um elemento "pré-discursivo" (p. 28), como algo que antecede a cultura e, por isso, é pertencente à ordem da natureza.

Durante a pesquisa de campo, essa demarcação binária também não passou despercebida, a ponto de ter sido observada e registrada por uma das pesquisadoras como uma prática recorrente para a organização de uma atividade de rotina das crianças na instituição.

A organização da fila para o lanche é realizada na maioria das turmas, de modo que a fronteira que separa o lugar de meninas do lugar de meninos é fortemente delimitada. Há grande afinco por parte das professoras e das auxiliares em ensinar para as crianças a necessidade da distinção dos espaços, marcada por um binarismo de gênero. As crianças, por sua vez, acabam aprendendo, ao longo do tempo, a se organizarem dessa maneira, o que pode ser percebido ao compararmos as turmas dos bebês, na qual a distinção de gênero quase não ocorre, com a turma de 5 anos, na qual a distinção é ressaltada de forma recorrente tanto pelos adultos quanto pelas próprias crianças.(Excerto extraído do diário de campo de uma das pesquisadoras)

Na perspectiva de Butler (2016), o gênero é compreendido por seus efeitos e, dentre estes, estão os substantivos, que se produzem e se estabelecem, por meio das identidades coerentes e unívocas, como modos "naturais" de ser. Gênero implica numa "estilização" do corpo (BUTLER, 2016, p. 242), que abrange os gestos, movimentos e estilos corporais repetidos no decorrer da vida, articulados na composição de um "eu” marcado pelo gênero. Não há, portanto, uma identidade preexistente pela qual um ato ou atributo de gênero possa ser definido. Para Butler (2016), são as performances sociais de gênero que constituem as identidades, sejam elas substantivas (marcadas pela coerência requisitada por 
uma inteligibilidade normativa), sejam elas outras configurações de gênero possíveis, que escapam da lógica do alinhamento sexo-gênero-desejo. São essas performatividades que criam a ideia de gênero e seus efeitos de subjetivação, os quais também se fazem notar nos corpos, em suas expressões e sentidos.

Convém ressaltar que, desde a mais tenra idade, as crianças, no interior das instituições educativas, estão cotidianamente aprendendo essas estilizações corporais, uma vez que os cuidados e a educação do corpo infantil são fortemente atravessados por processos de masculinização e feminilização (BUSSSIMÃO et al, 2010; VIANNA; FINCO, 2009). Gestos, movimentos, posturas e olhares das crianças ganham sentidos e são alinhavados socialmente. Nesta perspectiva, Vianna e Finco (2009) enfatizam que as relações das crianças na Educação Infantil são marcantes para que elas sejam introduzidas como meninos e meninas na vida social. Desse modo, é posta em execução uma educação corporal, como sinalizam Buss-Simão et al (2010), em que os corpos das crianças, ao serem cuidados e educados, são significados e marcados pelos adultos.

Consciente de que as crianças aprendem a se comportar conforme normas de conduta que correspondem a discursos sociais que são demarcadores das expressões de gênero na sociedade, a professora L percebe e comenta claramente como essa divisão binária se faz notar nos corpos das crianças.

\footnotetext{
Pesquisadora: E você acha que com isso está formando o corpo da criança?

Professora L: Acredito que sim. Porque com isso ela se reconhece.

Pesquisadora: Ela aprende, né?

Professora L: Ela aprende, ela vê que o menino é diferente dela. É que eles ainda não estão na fase de perguntar, mas logo eles vão ver e "por que que o corpo da menina é assim?".

Pesquisadora: E não só o corpo físico.

Professora L: Comportamental. O cabelo da menina é compridinho, vem com lacinho, sapatinho rosa com lacinho. E o menino não, é mais simples. Chega um momento que ela vai acabar fazendo essa pergunta e é difícil você explicar: "ela veio porque é menina, é delicada". Mas por que que o menino também não pode ser delicado, educado? Mas dizem "menina tem que ser delicada, menino não. Se você for delicado, você vai ser taxado de não homem".
}

As relações de gênero, no contexto institucional, deixam, também, seus rastros de incômodo, uma vez que remetem a um terreno arenoso, instável, problemático por excelência ao trazerem à tona um corpo que escapa da ordem do "natural" e do "inevitável" e, portanto, foge da lógica binária, definida pelo alinhamento do sexo ao gênero. O corpo deixa de ser sentido e pensado como uma máquina, como um organismo, e passa a ganhar uma realidade insólita e contraditória porque se insere na ordem do discurso e, portanto, se constitui como construção simbólica (LE BRETON, 2013a).

A segunda palavra chave retirada da caixa foi "sexualidade", que remeteu a uma situação específica de um menino da turma da professora $W$ e de sua relação com o pai e com a instituição.

Professora W: Olha, em relação à sexualidade, a gente é mais cobrada pelos pais. Porque essa questão que ela falou. Igual, lá na minha sala tem um menino que o pai manda uns brinquedos para o menino que eu fico meio abismada, sabe? E ele fala: "Esse menino é muito delicado." Esses dias ele mandou um pau de beisebol com uma bolinha e falou para o menino: "Hoje você pega isso aqui e o menino que vir você taca nele." E o menino é todo assim, delicadinho, amoroso. 
Ele sempre pergunta. Aí ele fica assim: "Eu queria brincar com as meninas de casinha, mas elas não querem deixar." As próprias crianças falam: "Vai brincar com os meninos!" É uma coisa tão assim, enraizada na sociedade, essa distinção entre feminino e masculino que eu fico pensando o quê que gera na cabeça dele. Esses dias ele veio com um caminhão de bombeiro desse tamanho. As crianças ficaram loucas pelo caminhão e ele colocava debaixo do braço e continuava mexendo nas panelinhas, e todo mundo querendo ver. E eu falava: "Por que que você trouxe esse brinquedo se você não quer brincar com ele?" "Meu pai mandou eu brincar com esse brinquedo hoje."

(...)

Quando coloca uma música clássica, ele se transforma, ele parece uma bailarina. Sabe aquela leveza, assim? Que tem no corpo? Aí, os meninos ficam todos olhando. As próprias crianças ficam observando o jeito que ele dança, assim, solto. E é tudo uma questão de sexualidade.

"A norma ronda os corpos meigos", afirma Preciado (2013, p. 98). Ainda que a professora mantenha uma relação com a criança e a compreenda de uma forma que tenta escapar de uma perspectiva normativa, sente-se impotente para transformar a sua inquietação diante do sofrimento da criança em um trabalho educativo que tenha ressonâncias na família. Sofrimento este que é produzido pelas insistentes investidas do pai para "consertar" o corpo do menino meigo e delicado a fim de torná-lo um menino agressivo, adequado à performance masculina construída socialmente para ser encarnada nos corpos de meninos e de homens. O discurso da professora, mesmo trazendo a voz da criança e com ela se implicando, resvala numa conformidade amparada nos poderes que compõem o conjunto de aparatos institucionais, representados pela família e pela escola, que, parafraseando Preciado, rondam o menino. Trata-se de uma política de gênero que vigia o berço, à espreita das crianças que vão nascer, de quem e como serão, para conformá-las à heterossexualidade (PRECIADO, 2013).

Da mesma forma, o corpo da criança vigiada, cercada em seu berço, leito ou quarto por toda uma ronda de parentes, babás, serviçais, pedagogos e médicos, todos atentos às mínimas manifestações de seu sexo, constitui, sobretudo a partir do século XVIII, outro "foco local" de poder-saber. (FOUCAULT, 2006, p. 109, grifo do autor)

A professora F, que já foi diretora do CMEI, também se posiciona no diálogo sobre o assunto, assumindo, junto com a professora $\mathrm{W}$, a sua indignação em relação às atitudes do pai do menino.

Professora F: Esse pai aí ele veio assim, então ele quer impor mesmo. A gente coloca às vezes: "Homem também tem leveza, ele pode ter e isso não quer dizer que ele deixa de ser homem”. E ninguém está falando que ele não é, né? Mas ele quer se impor tanto que a criança, a gente percebe um certo sofrimento nela. E como que a gente vai, chama esse pai e fala para ele? $\mathrm{O}$ homem, eu acho que se alguém falar, ele vem em cima, conhecendo ele. Porque a gente passa a conhecer os pais que a gente tem. A gente sabe com quem que a gente pode falar e quem que a gente não pode. E nisso a gente também sofre. Porque a gente pensa se pode fazer alguma coisa por aquela criança, e como que a gente faz isso sem criar um mal-estar? Com leveza? Porque a gente tem que conduzir a situação de uma forma leve, para esse pai entender que a criança vai deixar de sofrer um pouco. Para que esse pai entenda, compreenda que ele pode pedir ajuda. Que ele consiga entender para que essa criança não sofra mais.

É interessante observar que ambas as professoras, em seus discursos, por um lado, preocupam-se e são sensíveis à criança que sofre devido às atitudes impositivas do pai em relação a uma masculinidade normativa a que o menino deve, a todo custo, exercer. Por outro lado, os sentimentos de indignação e sofrimento pela dor da criança não se traduzem em ações provocadoras de mudanças, que estejam 
comprometidas com a discussão e a problematização dos diversos modos como as crianças vivem e podem viver seus gêneros e sexualidades. Seus conflitos se expressam sob a forma de dúvidas: o que fazer pela criança? Como fazer algo sem "criar um mal-estar"? Tarefa nada fácil para uma educação que ainda está muito pautada em uma visão teleológica da vida humana, para a qual há um roteiro a ser cumprido, no qual a heteronormatividade se estabelece como certeza.

Em seu manifesto em defesa da criança queer, Preciado (2013) contesta o assalto aos direitos das crianças às suas livres expressões de gênero e sexualidade, mas também aos direitos dos pais a serem pais dessas crianças, sem terem que se tornar seus maiores algozes. Os pais, ao invés de proteger e defender a criança, são acionados a assumirem o papel de "representantes repressivos da lei de gênero" (PRECIADO, 2013, p. 99). Na lógica perversa de um sistema educativo e social que impõe dolorosamente normas sexuais e de gênero, opera-se um estado de alerta e vigilância para, diante de toda e qualquer dissidência e transgressão, reagir com ameaças, intimidações, castigos e, até mesmo, a morte.

\section{Considerações finais}

O corpo da criança é, sem dúvida, uma questão basilar na Educação Infantil, se considerarmos o binômio educar-cuidar como um dos seus eixos. O que nos inquieta são os sentidos que esse binômio tem assumido nas mais diversas práticas educativas e nos processos de construção de propostas pedagógicas para a educação de crianças pequenas. Como esse corpo é compreendido? O que significa cuidar e educar o corpo da criança?

Como abordamos, o corpo, em suas manifestações mais singulares - gestos, movimentos, posturas e linguagens -, é alinhavado socialmente (VIANNA; FINCO, 2009). Desse modo, um dos primeiros alvos de padrões de condutas, das expectativas de desenvolvimento e das imagens sociais construídas em torno dos gêneros, na Educação Infantil, é o corpo da criança. Sobre ele é construída, nas palavras de Foucault (2006, p. 35), toda uma "ortopedia discursiva", que toma a sexualidade das crianças como o seu principal ponto de apoio. Sobre ele incidem os significados culturais que desenham fronteiras, ainda ensinadas como instransponíveis, entre os gêneros demarcados por uma relação mimética com um corpo assumido como substrato da natureza ao qual o sexo se acopla (BUTLER, 2016). Deste mesmo corpo, esperam-se performances que venham a se conformar com masculinidades e feminilidades demarcadas por essas rígidas fronteiras sustentadas pela correspondência biunívoca gênero-corpo sexuado. Estas performances são conteúdos importantes do roteiro a ser ensinado, conduzido e orientado por uma educação, tanto na família quanto na escola, amparada numa perspectiva de desenvolvimento mobilizada pela ideia de progresso e de um "dever ser", que apaga todas as outras possibilidades de existir que não estejam alinhadas ao que está determinado como norma.

Cabe destacar que não apenas as questões de gênero e sexualidade se fazem presentes nos processos de cuidado e de educação dos corpos das crianças, mas também os marcadores de raça, que incidem sobre esses corpos, sobretudo no tocante a uma estetização modelar e idealizada, que tem no 
corpo branco europeizado o signo da beleza. Demarcam-se, assim, normas, a serem aprendidas pelas crianças, que estão fortemente enraizadas em um racismo estrutural e constitutivo da sociedade brasileira, em que as pessoas negras e suas culturas são alvos de processos históricos de discriminação, produtores de profundas desigualdades sociais e violências.

Ainda que não tenhamos, neste artigo, nos dedicado a tratar das questões étnico-raciais como elementos importantes a serem considerados quando os cuidados e a educação dos corpos da criança estão em foco, temos a clareza de que a perspectiva feminista, ao se apresentar como um olhar crítico a ser lançado sobre os processos educativos de crianças pequenas, não pode se restringir ao gênero, mas sim debruçar-se sobre múltiplos vetores de opressão (OLIVEIRA, 2010). Nesse sentido, Brah (2006) aponta que uma abordagem interseccional, no campo dos estudos feministas, não pode assumir classe social, gênero, raça e sexualidade como "variáveis independentes" (p. 351), posto que cada uma destas estruturas marca uma opressão que está inscrita na outra, é constituída e se constitui pela outra. Com isto, é válido sinalizar a importância de pesquisas que assumam esta abordagem, com vistas a compreender e trazer à tona como, nos contextos educativos de crianças pequenas, estes marcadores sociais, também, incidem de forma articulada, produzindo realidades que denunciam opressões.

As reflexões que aqui levantamos pretendem ser provocadoras da urgente tarefa a ser assumida pela educação de dar visibilidade, de comprometer-se e responsabilizar-se por novas subjetividades que são silenciadas e sufocadas por modelos hegemônicos de sujeito gerenciados por uma ordem social e cultural que policia os corpos e nos impede de enxergar a infância, a educação, a vida e o mundo para além dos binarismos, que violam direitos e são produtores de práticas sexistas e racistas.

\section{Referências}

ARIÈS, Philippe. História social da criança e da família. Rio de Janeiro: Guanabara, 1981.

BRAH, Avtar. Diferença, diversidade, diferenciação. Cadernos Pagu, n. 26, 2006, p. 329-376.

BUSS-SIMÃO, Márcia; MEDEIROS, Francisco Emílio de; SILVA, Ana Márcia; FILHO, João Josué da Silva. Corpo e infância: natureza e cultura em confronto. Educação em Revista, vol. 26, n. 3, p. 151-168, 2010.

BUTLER, Judith. Problemas de gênero: feminismo e subversão da identidade. 10. ed. Rio de Janeiro: Civilização Brasileira, 2016.

FERREIRA, Marcelo Santana. Sobre crianças, sexopolítica e escrita de si. Revista Polis e Psique, vol. 6, n. 1, p. 51-64, 2016. 
FOUCAULT, Michel. História da sexualidade I: a vontade de saber. 17. ed. Rio de Janeiro: Edições Graal, 2006.

FOUCAULT, Michel. Ditos e escritos V: ética, sexualidade, política. 3. ed. Rio de Janeiro: Forense Universitária, 2014.

HARAWAY, Donna. "Gênero" para um dicionário marxista: a política sexual de uma palavra. Cadernos Pagu, n. 22, p. 201-246, 2004.

HARAWAY, Donna J. Manifesto ciborgue: ciência, tecnologia e feminismo-socialista. In: TADEU, Tomaz (org.). Antropologia do ciborgue: as vertigens do pós-humano. 2. ed. Belo Horizonte: Autêntica, p. 33-118, 2016.

LE BRETON, David. Antropologia do corpo e modernidade. 3. ed. Petróplis, RJ: Vozes, 2013 a.

LE BRETON, David. Adeus ao corpo: antropologia e sociedade. 6. ed. Campinas, SP: Papirus, 2013b.

OLIVEIRA, João Manuel. Os feminismos habitam espaços hifenizados - A localização e interseccionalidade dos saberes feministas. Ex aequo, n. 22, p. 25-39, 2010.

PRECIADO, Beatriz. Quem defende a criança queer. Jangada-crítica, literatura, artes, n. 1, Viçosa, p. 96-99, 2013.

VIANNA, Claudia; FINCO, Daniela. Meninas e meninos na Educação Infantil: uma questão de gênero e poder. Cadernos Pagu, n. 33, p. 265-283, 2009. 